\title{
PENGUKURAN LAJU PAPARAN RADIASI DAN EFEKTIVITAS DINDING SERTA PERISAI RADIASI RUANG PANORAMIK
}

\author{
${ }^{1}$ Haekal Ilmi, ${ }^{2}$ Dwi Rochmayanti \\ ${ }^{1)}$ Rumah Sakit Universitas Indonesia \\ ${ }^{2)}$ Poltekkes Kemenkes Semarang \\ E-mail : haekalilmi@gmail.com
}

\begin{abstract}
Background : The panoramic room at Radiological Installation in Sunan Kalijaga Hospital has a room divider in the form of radiation shield with a thickness of $7.5 \mathrm{~cm}$ which is visible only in the form of plywood and unknown thickness of lead in it, ideally radiation shield has a thickness equivalent to $2 \mathrm{~mm}$ of lead, but the barrier it's not. The purpose of this study is to determine the value of the ex posure rate and the effectiveness of walls and shields in the room.

Methods :The method of this research is quantitative, data collected by observing, survey and also documentation. Measurement of the exposure rate is measured at the time of exposure through walls and shields while measuring effectiveness is measured at the time before and after exposure through walls and shields. In order to drawing the conclusion, the data obtained then compared with the Perka No. 8 of 2011 to declare about the room safe or not. At the rate of exposure the limit is $1 \mathrm{mSv} /$ year for the general public and $20 \mathrm{mSv}$ for radiation workers, whereas the effectiveness should not exceed the $5 \%$ tolerance.

Results : The result of this research reveal that the measurement results of the rate of radiation exposure in the panoramic chamber has an average of $0.0538 \mathrm{mSv} / \mathrm{year}$ and is declared safe as it meets the standards. Effectiveness at some points has a tolerance value exceeding the limit, ie 50\% door, 16,667\% room divider, and 69,766\% glasspok, while on the right wall $1.389 \%$ and the rear wall $0 \%$ both have tolerance values below the limit.
\end{abstract}

Conclusion : Based on these results indicate that the overall measurement of radiation exposure is below the maximum limit. The average value is $0.0538 \mathrm{mSv} /$ year

Keywords :Measurement, Exposure, Panoramic

\section{Pendahuluan}

Pemanfaatan radiasi pengion telah banyak dimanfaatkan dalam kehidupan, salah satunya adalah dunia medis yang penerapannya melalui radiodiagnostik dan radioterapi. Penggunaan radiasi dibidang kesehatan bukan berarti tanpa efek samping, efek merugikan tersebut dapat terjadi apabila tubuh menerima paparan radiasi pengion dalam jumlah yang besar atau tidak memenuhi aturan standar yang berlaku. Dengan demikian diperlukan upaya secara terus menerus untuk melakukan pengendalian keselamatan dan kesehatan kerja radiasi melalui kegiatan proteksi radiasi berupa pemantauan paparan radiasi (Akhadi, 2000).

Ada tiga hal penting yang perlu mendapatkan perhatian untuk mencegah terjadinya kecelakaan radiasi, yaitu: adanya peraturan perundang-undangan dan standar keselamatan, pembangunan instalasi yang dilengkapi dengan sarana peralatan keselamatan kerja dan sarana pendukung lainnya yang sempurna sesuai dengan perencanaan yang telah ditetapkan sebelumnya, dan tersedianya personel dengan bekal pengetahuan yang memindai dan memahami sepenuhnya tentang keselamatan kerja radiasi (Akhadi, 2000). Keselamatan radiasi pengion diatur dan keamanan sumber radioaktif mengatur keselamatan radiasi terhadap pekerja, masyarakat, lingkungan hidup, keamanan sumber radioaktif dan inspeksi dalam pemanfaatan tenaga nuklir (PP No. 33 Tahun 2007).

Menurut Perka Bapeten No. 8 Tahun 2011, nilai batas dosis untuk pekerja radiasi yaitu, dosis efektif sebesar 20 $\mathrm{mSv} /$ tahun, sedangkan untuk masyarakat umum dosis efektif sebesar $1 \mathrm{mSv} /$ tahun.

Panoramik Topografi merupakan istilah yang digunakan untuk menunjukan teknik dalam menghasilkan sebuah irisan dari permukaan garis. Teknik Radiografi ini menghasilkan sebuah penggambaran panoramik dari seluruh mandibula meliputi Temporo Mandibular Joint (TMJ) dan sepanjang kedua arkus dental. (Ballinger, 1999). Persyaratan ruang pemeriksaan menurut Kemenkes No 1014 ruangan panoramik sendiri memiliki ketentuan dalam desain luas ruangan yaitu memiliki 3 Meter (panjang) x 2 Meter (lebar) x 2,8 Meter (tinggi), ketebalan dinding $25 \mathrm{~cm}$ (dua puluh lima sentimeter) bata merah atau beton $20 \mathrm{~cm}$ (dua puluh sentimeter) atau setara $2 \mathrm{~mm}$ timbal, ukuran kaca sesuai kebutuhan tebal $2 \mathrm{~mm}$ timbal.

Berdasarkan hasil pengamatan penulis, ruangan panoramik di Instalasi Radiologi RSUD Sunan Kalijaga Kabupaten Demak memiliki luas 3 meter (panjang) x 4 meter 
(lebar) x 4,33 meter (tinggi) ruang tersebut bersebelahan dengan ruang operator CT-Scan dengan dibatasi oleh pembatas berupa perisai radiasi dengan ketebalan keseluruhan pembatas 7,5 cm yang terlihat secara kasat mata hanya berupa kayu triplek dan tidak diketahui ketebalan timbal di dalamnya. Setiap akan digunakannya ruang panoramik maka radiografer yang sedang ada di dalam ruang operator CT-Scan harus keluar terlebih dahulu dikarenakan tinggi pembatas tidak menutup bagian atas ruangan. Menurut kepala ruangan Instalasi Radiologi RSUD Sunan Kalijaga Kabupaten Demak, ruangan tersebut tidak memiliki berkas atau hasil pengukuran tentang laju paparan di sekitar ruangan.

Penelitian ini dilakukan untuk mengetahui hasil pengukuran laju paparan radiasi dan efektivitas dinding pada sekitar ruang panoramik di Instalasi Radiologi RSUD Sunan Kalijaga Kabupaten Demak dan hasil pengukuran disesuaikan dengan Perka Bapeten No. 8 Tahun 2011.

\section{Metode}

Jenis Penelitian yang digunakan dalam penelitian ini adalah penelitian kuantitif dengan pendekatan survey yaitu penulis melakukan pengamatan dan pengukuran laju paparan di lokasi penelitian.

Penelitian dilakukan dengan mengukur pada beberapa titik, yaitu: pada pada Titik A pada jarak $335,5 \mathrm{~cm}$ dari sumber ke balik perisai, titik B pada jarak $327 \mathrm{~cm}$ dari sumber ke depan perisai, titik $C$ pada jarak $326 \mathrm{~cm}$ dari sumber ke balik pintu, titik D pada jarak 313 dari sumber ke depan pintu, titik E pada jarak $225 \mathrm{~cm}$ dari sumber ke balik kaca intip, titik F pada jarak $227 \mathrm{~cm}$ dari sumber ke depan kaca intip, titik G pada jarak $111 \mathrm{~cm}$ dari sumber ke balik dinding disebelah belakang sumber, titik $\mathrm{H}$ pada jarak $96 \mathrm{~cm}$ dari sumber ke depan dinding disebelah belakang sumber, titik I pada jarak $219 \mathrm{~cm}$ dari sumber ke balik dinding disebelah kanan sumber, titik J pada jarak $204 \mathrm{~cm}$ dari sumber ke depan dinding disebelah kanan sumber.

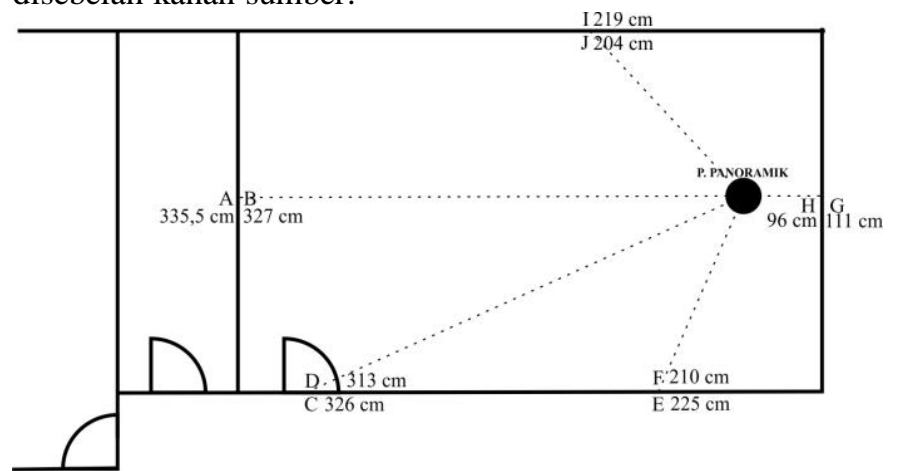

Gambar 1. Titik Pengukuran (1) Pesawat Panoramik, (A) Belakang tabir pemisah ruang panoramik dengan ruang operatorCTScan, (B) Depan tabir pemisah ruang panoramik dengan ruang operator CT-Scan, (C) Belakang pintu di ruang pemeriksaan panoramik, (D) Depan pintu di ruang pemeriksaan panoramik, (E) Belakang kaca intip di ruang pemeriksaan panoramik, (F) Depan kaca intip di ruang pemeriksaan panoramik, (G) Belakang dinding ruang panoramik dibelakang pesawat panoramik, $(\mathrm{H})$ Depan dinding ruang panoramik dibelakang pesawat panoramik, (I) Belakang dinding ruang panoramik sebelah kanan pesawat panoramik, (J) Depan dinding ruang panoramik sebelah kanan pesawat panoramik

Setelah itu menghitung efektivitas dinding dan perisai radiasi (Candra dan Eko, 2016) yaitu dengan menggunakan rumus sebagai berikut:

Efektivitas $(\%)=($ Do-Da $) /$ Do $\times 100 \%$

Do $=$ Pengukuran laju paparan radiasi di depan tabir

Da = Pengukuran laju paparan radiasi di balik tabir

Setelah data diperoleh, kemudian data disajikan dalam bentuk tabel. Dari hasil pengukuran tersebut kemudian dibandingkan dengan NBD (Nilai Batas Dosis) pada Perka Bapeten No. 8 tahun 2011 tentang keselamatan radiasi dalam penggunaan pesawat sinar- $x$ radiologi diagnostik dan intervensional pada paragraf 2 tentang limitasi dosis pasal 31a dan pasal 32a dimana pekerja radiasi tidak boleh melampaui Nilai Batas Dosis $20 \mathrm{mSv} /$ tahun dan pada masyarakat umum tidak boleh melampaui Nilai Batas Dosis $1 \mathrm{mS} /$ tahun.

\section{Hasil dan Pembahasan}

\section{Hasil pengukuran laju paparan radiasi pada ruang panoramik}

Pengukuran menggunakan Surveymeter dengan skala $1000 \mu \mathrm{Gy} / \mathrm{h}$ dan faktor kalibrasi 0,95 . Hasil pengukuran laju paparan radiasi di ruang pemeriksaan panoramik RSUD Sunan Kalijaga Kabupaten Demak disajikan dalam bentuk tabel sebagai berikut:

Tabel 1. Pengukuran Laju Paparan Radiasi

\begin{tabular}{cccccc}
\hline $\begin{array}{c}\text { Titik } \\
\text { Pengukuran }\end{array}$ & $\begin{array}{c}\text { Jarak Titik } \\
\text { Pengukuran } \\
(\mathrm{cm})\end{array}$ & $\begin{array}{c}\text { Rata } \\
\text { - rata } \\
\text { Hasil } \\
\text { Baca }\end{array}$ & $\begin{array}{c}\text { Skala } \\
(\mu \mathrm{Gy} / \mathrm{h})\end{array}$ & $\begin{array}{c}\text { Faktor } \\
\text { Kalibrasi }\end{array}$ & $\begin{array}{c}\text { Hasil } \\
\text { Ukur } \\
(\mu \mathrm{Gy} / \mathrm{h})\end{array}$ \\
\hline A & $335,5 \mathrm{~cm}$ & 0,010 & 1000 & 0,95 & 9,5 \\
C & $326 \mathrm{~cm}$ & 0,020 & 1000 & 0,95 & 19 \\
E & $225 \mathrm{~cm}$ & 0,020 & 1000 & 0,95 & 19 \\
G & $111 \mathrm{~cm}$ & 0,013 & 1000 & 0,95 & 12,667 \\
I & $219 \mathrm{~cm}$ & 0 & 1000 & 0,95 & 0 \\
\hline
\end{tabular}

Karena satuan internasional menggunakan Sievert (Sv), maka hasil ukur di konversi ke Sievert seperti pada tabel 2.

Tabel 2. Konversi Hasil Ukur Laju Paparan Radiasi dari $\mu \mathrm{Gy} / \mathrm{h}$ ke $\mathrm{mSv} / \mathrm{h}$

\begin{tabular}{ccc}
\hline Titik Pengukuran & Hasil Ukur $(\mu \mathrm{Gy} / \mathrm{h})$ & Hasil Ukur $(\mathrm{mSv} / \mathrm{h})$ \\
\hline A & 9,5 & 0,001 \\
C & 19 & 0,019 \\
E & 19 & 0,019 \\
G & 12,667 & 0,013 \\
I & 0 & 0 \\
\hline
\end{tabular}

Pada ketentuan pemerintah laju paparan menggunakan satuan mSv/tahun, maka hasil diatas dikali lama penyinaran $17,6 \mathrm{~s}(0,0049 \mathrm{~h})$ dikalikan rata-rata banyaknya pemeriksaan setiap bulan (76 pemeriksaan) dikali jumlah bulan dalam satu tahun (12 bulan) sehingga diperoleh hasil pada tabel 3 . 
Tabel 3. Konversi Hasil Ukur Laju Paparan Radiasi dari mSv/h

\begin{tabular}{cccccc}
$\begin{array}{c}\text { Titik } \\
\begin{array}{c}\text { Pengukur } \\
\text { an }\end{array}\end{array}$ & $\begin{array}{c}\text { Hasil } \\
\text { Ukur } \\
(\mathrm{mSv} / \\
\text { h) }\end{array}$ & $\begin{array}{c}\text { Lama } \\
\text { Penyinar } \\
\text { an }\end{array}$ & $\begin{array}{c}\text { Banyak } \\
\text { Pemeriksa } \\
\text { an }\end{array}$ & $\begin{array}{c}\text { Jumla } \\
\text { h } \\
\text { bulan }\end{array}$ & $\begin{array}{c}\text { Hasil } \\
\text { Ukur } \\
(\mathrm{mSv} / \mathrm{tahu} \\
\text { n) }\end{array}$ \\
\hline A & 0,001 & 0,005 & 76 & 12 & 0,042 \\
C & 0,019 & 0,005 & 76 & 12 & 0,085 \\
E & 0,019 & 0,005 & 76 & 12 & 0,085 \\
G & 0,013 & 0,005 & 76 & 12 & 0,057 \\
I & 0 & 0,005 & 76 & 12 & 0 \\
\hline
\end{tabular}

\section{Hasil pengukuran efektivitas dinding dan perisai} radiasi

Hasil pengukuran efektivitas dinding perisai di ruang pemeriksaan panoramik RSUD Sunan Kalijaga Kabupaten Demak disajikan dalam bentuk tabel sebagai berikut:

Tabel 5. Pengukuran Hasil Ukur Efektivitas

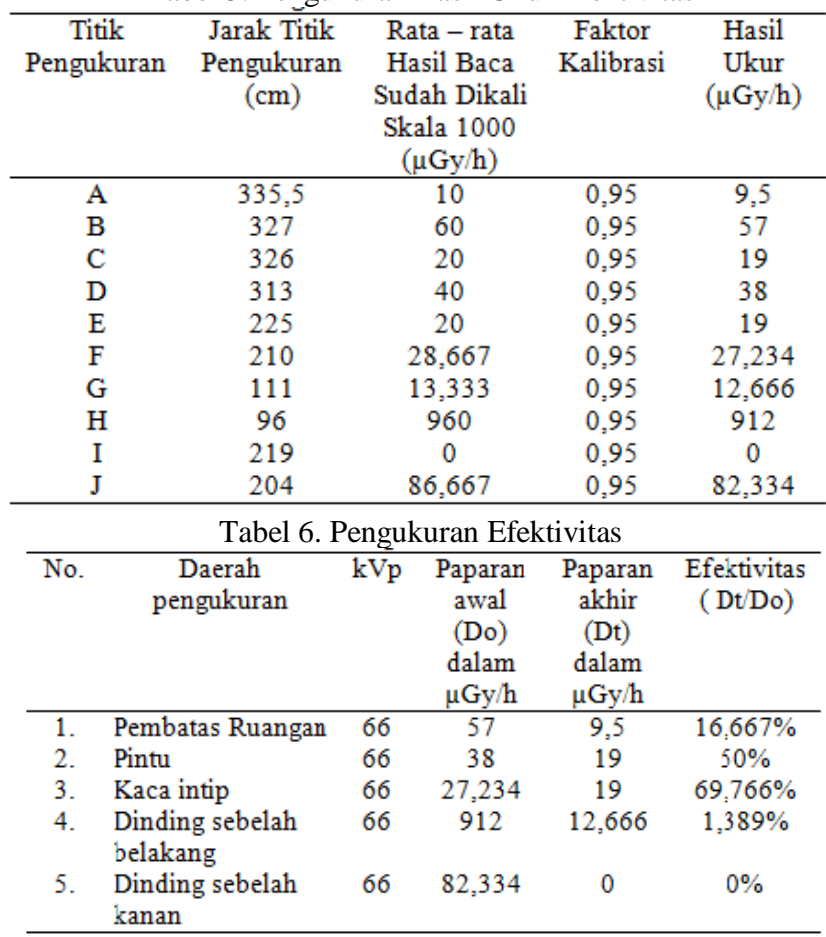

\section{Laju Paparan}

Untuk mengetahui tingkat keamanan laju paparan radiasi suatu daerah, penulis menggunakan Perka Bapeten No. 8 Tahun 2011 tentang NBD (Nilai Batas Dosis) untuk pekerja radiasi yaitu, dosis efektif sebesar $20 \mathrm{mSv} / \mathrm{tahun}$, sedangkan untuk masyarakat umum dosis efektif sebesar 1 $\mathrm{mSv} /$ tahun.

Berdasarkan hasil pengukuran laju paparan pada 5 titik di ruang panoramik, semua titik tersebut dinyatakan berada dibawah batas NBD. Titik $\mathrm{E}$ memiliki nilai tertinggi dikarenakan jarak sumber radiasi yang dekat dengan titik pengukuran dan dimungkinkan terjadinya pemuaian pada kaca intip, sehingga memiliki nilai yang cukup besar. Titik $\mathrm{C}$ juga memiliki nilai tertinggi, meskipun jaraknya lebih jauh dari titik $\mathrm{E}$ namun dikarenakan kondisi engsel yang tidak berfungsi dengan baik sehingga pintu tidak dapat menutup rapat dan membuat celah yang cukup lebar pada pintu. Titik $G$ memiliki nilai yang lebih rendah dari titik $\mathrm{C}$ dan $\mathrm{E}$ dikarenakan jaraknya yang paling dekat dengan sumber radiasi, meskipun memiliki dinding yang sudah memenuhi persyaratan namun nilai yang terukur cukup besar. Titik A memiliki nilai yang lebih rendah dari titik $\mathrm{C}, \mathrm{E}$, dan $\mathrm{G}$, dikarenakan bahannya yang terbuat dari kayu triplek dan adanya tambalan pada bagian sambungan kayu, meskipun jaraknya paling jauh dari sumber radiasi, nilai yang terukur cukup besar. Titik I memiliki nilai yang paling rendah dikarenakan dinding masih terbilang baik membuat tidak adanya paparan radiasi dibalik dinding.

\section{Efektivitas}

Brennan cit. Gusti 2015, menyatakan bahwa untuk mengetahui nilai kecukupan suatu daerah, penulis menggunakan ketentuan yang telah ditetapkan oleh Douglas J. Simpkin dan P.C. Brennan, tentang nilai kecukupan lead apron yaitu mendapatkan toleransi sebesar 5\% radiasi yang diteruskan. Pedoman ini sebenarnya digunakan untuk lead apron, karena dinding serta tabir pembatas memiliki kesamaan yaitu sebagai perisai manusia dari paparan radiasi maka di asumsikan sama.

Pada pintu, pembatas ruangan, dan kaca intip memiliki nilai toleransi yang melebihi batas, sedangkan pada dinding sebalah kanan dan belakang memiliki nilai toleransi dibawah batas. Kaca intip memiliki nilai toleransi tertinggi dikarenakan jaraknya yang dekat dengan sumber dan dimungkinkan adanya pemuaian pada kaca intip. Pintu juga memiliki nilai toleransi yang tinggi dikarenakan engsel pintu yang tidak cukup baik membuat pintu tidak dapat tertutup rapat dan membuat celah cukup lebar pada pintu. Pembatas ruangan memiliki nilai toleransi tinggi meskipun nilainya lebih rendah dari pintu dan kaca intip, dikarenakan bahan yang digunakan dan ketebalannya tidak sesuai dengan ketentuan pemerintah, dimana bahan harus memiliki ketebalan setara $2 \mathrm{~mm} \mathrm{~Pb}$. Dinding bagian belakang meskipun memiliki nilai toleransi dibawah batas, namun masih memiliki nilai yang terukur, dikarenakan jaraknya yang paling dekat dengan sumber radiasi. Dinding bagian kanan memiliki nilai toleransi terkecil dikarenakan kualitas dinding yang terbilang masih baik.

\section{Simpulan}

Pada hasil pengukuran laju paparan radiasi di ruang panoramik memiliki rata-rata $0,0538 \mathrm{mSv} /$ tahun. Sedangkan untuk hasil pengukuran efektivitas, pada kaca 
intip 69,766\%, pintu 50\%, pembatas ruangan $16,667 \%$, dinding sebelah belakang $1,389 \%$, dan dinding sebelah kanan $0 \%$.

Pada hasil pengukuran laju paparan seluruh titik dinyatakan aman karena tidak melebihi NBD yaitu 1 $\mathrm{mSv} /$ tahun untuk masyarakat umum dan $20 \mathrm{mSv} / \mathrm{tahun}$ untuk pekerja radiasi. Pada hasil efektivitas beberapa titik memiliki nilai toleransi melebihi batas, yaitu pintu, pembatas ruangan, dan kaca intip, sedangkan pada dinding bagian kanan dan dinding bagian belakang memiliki nilai toleransi dibawah batas, untuk nilai batas toleransinya yaitu $5 \%$.

\section{Saran}

Keterbatasan penelitian adalah peneliti tidak melakukan pengukuran pada bagian atas tabir pembatas yang terbuka. Alangkah baiknya dilakukan pengukuran diatas sekat diatas tabir pembatas dimana kemungkinan ada potensi paparan radiasi yang lebih tinggi di daerah tersebut.

Selama ini upaya proteksi adalah dengan keluar ruangan, namun saat flow / alur pasien CT-Scan dan panoramik meningkat sebaiknya dilakukan pengamanan perisai yang full.

\section{Daftar Pustaka}

Akhadi, M, 2000. Dasar-dasar Proteksi Radiasi PT. Rineka Cipta Jakarta.

Peraturan Pemerintah No 33 Tahun 2007. Tentang Radiasi Pengion dan Keselamatan Sumber Radioaktif.

Ballinger, Philip W. 1999. Radiographic Positioning and Radiologic Procedures.Edisi Sepuluh. St Louis: Mosby.

PERMENKES No. 1014/MENKES/SK/XI/2008. Tentang Standar Pelayanan Radiologi Diagnostik di Sarana Pelayanan Kesehatan.

Rasad, S, 2005. Radiologi Diagnostik Balai Penerbit Fakultas Kedokteran Universitas Indonesia.Jakarta.

NCRP, 2004. Structural Shielding Design for Medical XRay Imaging FacilitiesUnited Nations Scientific Commite on the Effects of Atomio Radiation.

Peraturan Kepala Badan Pengawas Tenaga Nuklir No. 8 Tahun 2011. Tentang Keselamatan Radiasi Dalam Penggunaan Pesawat Sinar-X Radiologi Diagnostik dan Intervensional.

Bushong, S.C. 2001. Radiologic Science for Technologist Physic, Biology and Protection, foruth edition, CV Mosby Company: Wasington DC.

Anonim, 2018. Jenis Detektor Radiasi, http://www.batan.go.id/ pusdiklat/elearning/Pengukuran_Radiasi/Pot eksi_00.htm. Diakses pada tanggal 14 Januari 2018.
Haditjahyono, Hendriyanto, 2018. Pusdiklat-Batan. Jakarta: http:/www.batan.go.id/pusdiklat/Pengukura n_Radiasi/Proteksi_02.htm. Diakses pada tanggal 2 Januari 2018.

Statkeiwicz, M, Kussel, E. 2000. Radiation Protection for Student Radiographer.CV Mosby Company, St Louis.

SK Kepala BAPETEN No. 01 Tahun 1999. Tentang Panduan Penyusunan Program Proteksi dan Keselamatan Radiasi Dalam Kegiatan Well Logging.

Rini, Siti, Edy, Yeti, Ardi, Darmini, Bagus, Rasyid, Emi, 2017. Proteksi Radiasi Bidang Radiodiagnostik dan Intervensional. Inti Media Pustaka. Magelang

(UNSCEAR), 2000. Exposure from natural sources of radiation.

Candra, Eko, 2016. Analisis Dosis Paparan Radiasi Pada Instalasi Radiologi Dental Panoramik. Youngster Physics Journal.

Brennan, 2004. Protective aprons in imaging departments: manufacturer stated lead equivalence values require validation. St Anthony's, Herbert Avenue, Dublin 4, Ireland.

Gusti, 2015. Pengujian Lead Apron di Instalasi Radiologi RSUD Banyumas. Poltekkes Semarang; Semarang. 